\section{Race is on to win Australian funding for big science projects}

Peter Pockley, Sydney

The Australian government has opened a competition among groups of researchers for A $\$ 155$ million (US\$76 million) to build major scientific facilities.

Several telescope projects and a synchrotron are already in the frame for the funding, which was announced this month by science minister Nick Minchin. But with statements of intent needed within a week of the announcement, and applications due by 11 May, the money is expected to go to projects that are already well planned.

Such proposals include the scheme from a consortium of nine universities for a synchrotron called Boomerang. Physicist John Boldeman, facility director of the Australian Synchrotron Research Program, says that Boomerang would be a 3 gigaelectron volt ring with nine beamlines.

The location for the synchrotron has yet to be decided, but three state governments, Queensland, Victoria and New South Wales, say that with the help of local industry they could raise the matching funds the government is demanding of successful project applicants.

Astronomers, meanwhile, are proposing several options for investment — although they may struggle to raise the matching funds. Rachel Webster, a physicist at the University of Melbourne and chair of the National Committee for Astronomy, says that the top priority is to double Australian time on 8-metre telescopes, either by greater participation in the Gemini project or by joining the European Southern Observatory.

But astronomers at the University of New South Wales want to build a 2-metre, wide-field infrared telescope in Australian Antarctic Territory. A fourth telescope plan would build a 6.5 -metre, wide-field optical telescope in Chile.

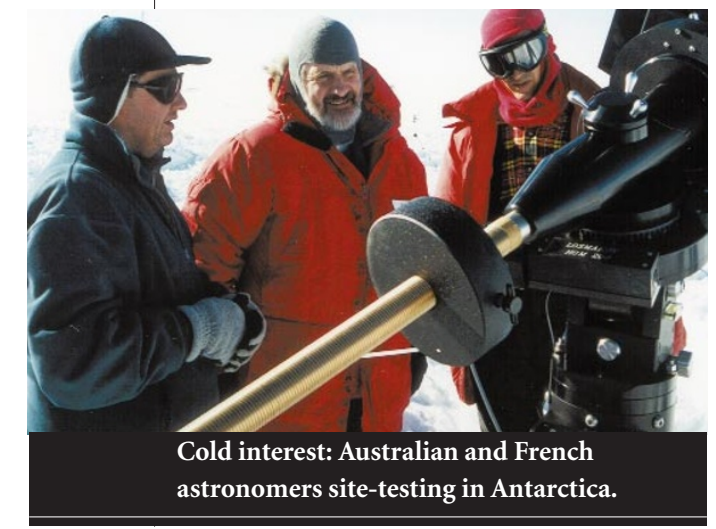

\title{
Japan's academics get green light to make their fortunes
}

David Cyranoski, Tokyo

From now on, the sky's the limit for academic entrepreneurs in Japan. The government has removed a $¥ 6$ million (US\$50,000) ceiling on the amount that researchers at public universities are allowed to earn from government-held patents based on their work.

Removing the limit is the latest of several steps designed to encourage academics to pursue the industrial applications of their work. The Japanese government holds the patent rights for much of the research done at public universities. And the number of patents granted on university-based science in Japan has been growing steadily in recent years (see graph), having jumped almost fivefold over the past 10 years. But many of these lie unused.

Restrictions preventing technology licensing offices from dealing with government-held patents were also removed last week. Seventeen such offices have opened in affiliation with Japanese universities since a 1998 law permitted them to be set up.

These policy changes could persuade researchers to be more active in pursuing applications for their work, says Takafumi Yamamoto, president of the Center for Advanced Science and Technology Incubation (CASTI), a licensing office at the University of Tokyo. "The government is no longer saying that it's bad to make money," he says.

CASTI's recent success has paved the way for an additional office funded by Tokyo University researchers themselves. The Advanced Science and Technology Enterprise Corporation, which opens in April, will focus on developing basic science discoveries into marketable products.

Researchers at the Institute of Physical and Chemical Research (RIKEN) are also catching on: 16 researchers there have invested in a venture business that will next month start to patent and license ideas from RIKEN.

The current burst of activity is regarded by some as a sign of how far Japan lags behind other countries in encouraging moneymaking by academics. "The really surprising thing about the $¥ 6$ million limitation is that it was still on the books at all," says Yukio Kato, manager of Waseda University's Intellectual Property Center in Tokyo.

Other obstacles to getting and using patents remain. Whereas a provisional application procedure allows US researchers, for example, to file patents at a minimal cost, Japanese researchers have to spend $¥ 300,000-400,000$ in filing an initial applica-

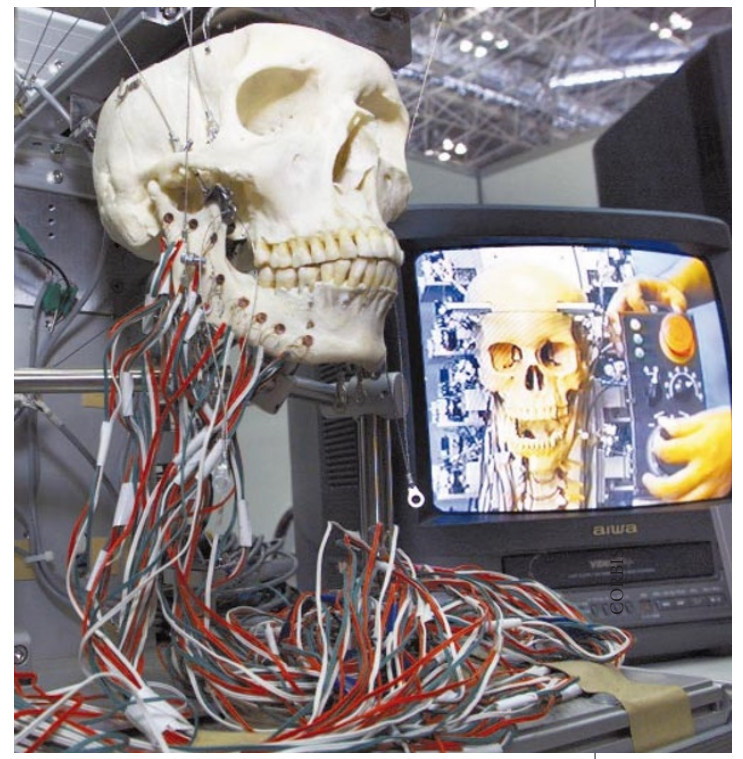

Profitable tool of the trade: a mastication robot developed by researchers at Waseda University.

tion. And any new business is legally required to demonstrate that it has at least $¥ 10$ million in capital. "This makes it hard for people to take a chance by starting on a small scale with a new technology," says Yoichi Okabe, director of the Research Center for Advanced Science and Technology at the University of Tokyo.

Other restrictions prohibit interactions between academia and industry. As public servants, for example, university researchers are not allowed to use their university e-mail for business matters. There are also strict restrictions on holding stocks and taking up stock options.

Some observers say that the system can only be substantially reformed after a proposed increase in university autonomy, tentatively scheduled for 2003 (see Nature 401, 198; 1999).

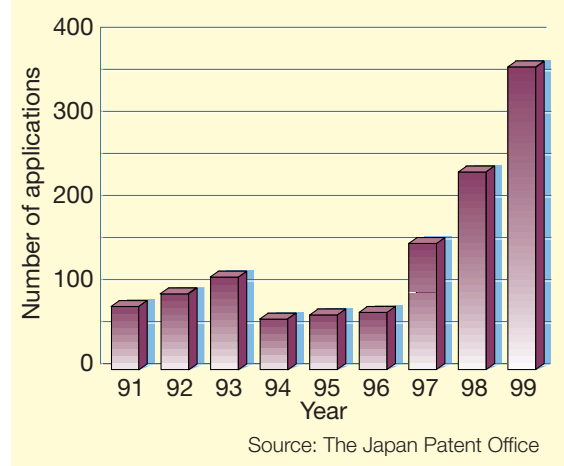

A patent increase: changes in the number of patent applications from Japan's universities. 